\title{
Another Look at Mode Intentionalism
}

\author{
Jonathan Mitchell ${ }^{1}$
}

Received: 8 November 2019 / Accepted: 18 August 2020 / Published online: 12 September 2020

(c) The Author(s) 2020

\begin{abstract}
A central claim in contemporary philosophy of mind is that the phenomenal character of experience is entirely determined by its content. This paper considers an alternative called Mode Intentionalism. According to this view, phenomenal character outruns content because the intentional mode contributes to the phenomenal character of the experience. I assess a phenomenal contrast argument in support of this view, arguing that the cases appealed to allow for interpretations which do not require positing intentional modes as phenomenologically manifest aspects of experience.
\end{abstract}

Intentionalist views in the philosophy of mind come in several varieties. However, all such views are concerned with the question of what it is about experience that determines what-it-is-like. In other words, Intentionalist views of all stripes provide an answer to the question of what properties or features of experience determine its phenomenal character. It is principally in the details of their answers to this question that varieties of Intentionalism differ. This paper considers a phenomenal contrast argument for the view that two things determine the phenomenal character of intentional experience, namely intentional content and intentional mode. I call this view Mode Intentionalism. My central claim is that this argument is unsuccessful.

The cases discussed are sense-perceptual experiences. Part of the motivation for this restriction is that they are paradigm intentional experiences, as personal level mental states which (relatively) non-controversially exhibit both intentionality and phenomenal character. So, if we want to understand the relation between the intentional and the phenomenal, then sense-perceptual experiences are an excellent place to start. Given this, I don't consider how the claims that follow map onto intentional experience per se.

Let me note, however, this restriction means I won't be considering arguments on behalf of Mode Intentionalism which draw on putatively non-content based phenomenal contrasts among cognitive intentional experiences. These could be contrasts

Jonathan Mitchell

jonathan.mitchell@manchester.ac.uk

1 University of Manchester, 24 Oaks Road, Kenilworth, Warwickshire CV8 1GE, UK 
between (1) conscious thoughts (e.g. judging that $\mathrm{P}$ vs wondering that $\mathrm{P}$ ); (2) conscious thoughts and imaginations (e.g. consciously thinking that the Eiffel Tower has a certain colour vs imagining that it does); or (3) across imaginative states. Although I do consider a contrast between sense-perception and imagistic memory. Important works in the literature seek to motivate views approximating to Mode Intentionalism in such ways. ${ }^{1}$ A comprehensive case against Mode Intentionalism would, therefore, deal with such cases. The more limited conclusion offered in this paper is that the arguments considered do not sufficiently motivate Mode Intentionalism about senseperceptual experience. I save consideration of whether the relevant phenomenal contrast arguments might support Mode Intentionalism about cognitive intentional experiences for a separate occasion.

What follows is also a limited defence of a Strong Intentionalist position-that phenomenal character is exclusively determined by intentional content-against Mode Intentionalism. Although this should be seen primarily as a via negativa, making an indirect case for Strong Intentionalism by showing an alternative view implausible.

The road map is as follows. Section 1 outlines minimal Intentionalist commitments, distinguishes Intentionalist views, and clarifies Mode Intentionalism. Section 2 presents the phenomenal contrast argument for Mode Intentionalism. Section 3 considers a critical response to it. Section 4 shows that the Mode Intentionalist's responses to the criticisms levelled fail to convince. Finally, Sect. 5 considers an associated view I call Intentionalism about Mode, explaining how it relates to issues considered in the previous sections.

\section{Intentionalism and Mode Intentionalism}

\subsection{Minimal Commitments and Varieties of Intentionalism}

Intentionalist views take on board minimal commitments. The most basic is that conscious experiences exhibit directedness towards their objects, where objects can be understood in the broad sense as covering physical particulars, persons, events, and states of affairs involving these things - as the target or focus of the experience. The so-called 'Intentional Object' of the experience is therefore given in answers to questions like 'what is your experience about' or 'what is your mind directed toward'. ${ }^{2}$ Furthermore, intentional experiences do not present bare particulars. Rather they present their objects under specific aspects-the so-called aspectual shape of the experience. ${ }^{3}$ For example, a visual experience of a desk does not merely present the desk per se, but presents it as being thus and so; for example, as

\footnotetext{
1 See Horgan and Tienson (2002: 520-533) and Siewert (2011: 236-267).

${ }^{2}$ We can remain neutral on complex issues concerning intentional objects, i.e. whether they are objects in the ordinary sense (see Searle 1983: 18, 117), or whether we need some intentional inexistence claim (see Crane 2001: 13-18 for discussion).

3 See Searle (1983: 12-13, 52, 1992: 155-157) and Crane (2000: 3, 2001: 18-22, 2003: 7-8).
} 
looking a certain shade of brown. It is on this basis that the experience has accuracy conditions.

Combining these points, we can formulate a minimal notion of intentional content: The object presented, as it presented to the subject under a specific aspect. This notion of intentional content, which I paraphrase as manifest content, is a first-person phenomenological notion. It is intended to capture, at least partly, how things seem from the subject's perspective. ${ }^{4}$ This minimal notion does not take a stand on whether the relevant object, so presented under a specific aspect in intentional experience, has a propositional structure. It is implausible that the manifest content of sense-perceptual experience has the structure of a proposition, singular or otherwise, but this issue won't concern me here. ${ }^{5}$

Let me now explain how such commitments relate to phenomenal character. As noted in the Introduction, Intentionalist views seek to answer the question of what determines the phenomenal character of experience. However, the question is ambiguous. We can read it metaphysically: 'what is it that metaphysically determines the phenomenal character of experience', where this might be features of experience beyond the subject's ken (i.e. not necessarily capturing how things seem from the subject's perspective). Alternatively, we can read it phenomenologically: 'what captures how things are experientially for the subject, or how it is with me'. ${ }^{6}$ As I will be understanding Intentionalism, such views seek (first and foremost) to provide an answer to the latter question. They seek to specify what-it-is-likeness in terms of properties of experience that are phenomenologically manifest, where this means is a part of the phenomenology of the experience that a sufficiently attentive subject could (in principle) pick out-introducing the notion of intentional content as manifest content reflects this commitment. ${ }^{7}$

Importantly though, 'things' in the phrase how things are with me (or 'it' in whatit-is-likeness), need not be read as exclusively referring to how the object of the experience seems. That would prejudice in favour of the view-which I call Strong Intentionalism below-that manifest content exhaustively determines phenomenal character. ${ }^{8}$ Before investigation, we should not rule out whether 'how things seem' includes dimensions of intentional experience which are not to be equated with manifest content.

Given what we have said so far Intentionalist views commit to the claim that manifest content plays a role in determining phenomenal character. As such, changes or differences in the manifest content of an experience will typically be reflected in changes or differences in its phenomenal character. Compare two sequential visual experiences, had by the same subject, of an object which changes colour every 30 seconds. First, they have a visual experience of it as red, and then 30 seconds

\footnotetext{
${ }^{4}$ See Siegel (2010: Ch.2).

5 See Crane (2009b: 452-469).

6 See Martin (1998a: 157-79) and Crane (2009a: 487).

7 For further clarification of the notion of the phenomenologically manifest, see Kriegel (2007: 115136).

${ }^{8}$ See Crane (2009a: 484-486) (cf. Byrne: 2001: 199-240).
} 
later as green. The first experience, $\mathrm{E} 1$ (at $\mathrm{t} 1$ ) has a manifest content approximating to $<\mathrm{O}$ as red $>$; the second, E2 (at $\mathrm{t} 2$ ), $<\mathrm{O}$ as green $>$. The different visual experiences present the same intentional object under different aspects, namely as having different observable colour properties. As such, the manifest content of E1 and E2 differ. Yet given this difference in manifest content, there will be a difference in phenomenal character. What-it-is-like to have a visual experience of the object as red is different from what-it-is-like to have a visual experience of the object as green. So, manifest content to some extent determines the phenomenal character of experience.

Here are three Intentionalist views which differ on the extent to which that is the case.

Strong Intentionalism: The phenomenal character of an intentional experience is entirely determined by its manifest content. Phenomenal character does not outrun manifest content. ${ }^{9}$

So, any difference in phenomenal character is necessarily a difference in manifest content_all phenomenal differences are manifest content differences. This can be expressed by the claim that phenomenal character supervenes on manifest content: No phenomenal difference without a difference in manifest content. I have more to say about Strong Intentionalism in what follows, but here are two alternatives.

Weak Intentionalism: The phenomenal character of an intentional experience is determined by its manifest content and non-intentional features (e.g. non-intentional qualia). Phenomenal character outruns manifest content. ${ }^{10}$

Weak Intentionalism claims that differences in phenomenal character are not exhausted by differences in manifest content since the phenomenal character of an intentional experience is also determined by the relevant non-intentional qualia. I won't have anything more to say about Weak Intentionalism.

Mode Intentionalism: The phenomenal character of an intentional experience is determined by its manifest content and the intentional mode of the experience. Phenomenal character outruns manifest content but does not outrun intentional structure. $^{11}$

\footnotetext{
${ }^{9}$ Approximations of this view are defended by Dretske (2000), Tye (1995, 2000, 2002: 137-151, 2014: 39-57), Harman (1990: 31-52) and Byrne (2001: 199-240). Although some of these authors have additional metaphysical commitments relating to the notion of content as representational content (see end of section). Mendelovici (2013: 135-5) argues for Strong Intentionalism in the case of emotions and moods, and Bain (2003: 502-523) does so in the case of pain.

${ }^{10}$ Qualia realists defend approximations of this view. See Block (1996: 19-49, 2003: 165-200), and Shoemaker (1996: ch.5, ch.6). Kind (2003: 225-244) and Peacocke (1983) [see Dennett (1988) and Martin (1998a: 157-179) for scepticism about non-intentional qualia; also see Crane (2003: sections 4 and $5)$ ].

${ }^{11}$ See Crane (2000: 1-11, 2001: ch1, 2003: 1-27, 2009a: 474-491), Horgan and Tienson (2002; 52033) and Chalmers (2004: 153-181). A precursor to this view is arguably found in Searle (1983: 4-6, 12) and in Block's notion of mental paint (see Block 1996: 19-49, 2003: 165-200). Deonna and Teroni (2012) argue for a similar view of emotions.
} 
Mode Intentionalism differs from Weak Intentionalism since it does not include any non-intentional qualia in the determination of phenomenal character. It claims that the phenomenal character of an intentional experience is entirely determined by its intentional structure, where this includes more than just manifest content since it also includes the relevant intentional mode (see Sect. 1.2 for clarification). ${ }^{12}$

Note, there is a further view in the vicinity of Mode Intentionalism which I consider at pertinent points during this paper, and discuss in detail in Sect. 5-namely what I call Intentionalism about Mode. This view has it that the relevant intentional mode may not only make a phenomenological difference (such that phenomenal character is partly determined by mode) but also makes a difference to intentional content. In other words, Intentionalism about Mode commits to a kind of modecontent. I mention this view here to bring the reader's attention to it since it will be relevant at specific points. Although Mode Intentionalism, as defined above, is my primary focus in the following sections.

As I have framed these varieties of Intentionalism, they are phenomenological views in that they specify what-it-is-likeness in terms of properties or features of experience that are phenomenologically manifest. Further to this, they operate with a notion of manifest content (and other relevant features of experience) that is not metaphysically committed. As such, they don't require any specific metaphysics of content (i.e. psychosemantics). In that sense, Strong Intentionalism, for example, should not be confused with Externalist Representationalism, which commits to a specific view of the content-determining relation between the metaphysics and the phenomenology. On such views, what exhaustively determines the phenomenal character of experience is its intentional content. However, that content is a specific kind of representational content, where (1) features of that content need not be phenomenally manifest to the subject, and (2) that content is itself determined by a specific causal relation to the environment (for example, the tracking of environmental features). ${ }^{13}$ One could hold a Strong Intentionalist view, as I have framed it, without an externalist psychosemantics, or indeed any view of the determining relation between the metaphysics (of content) and the phenomenology. This will be all I say on this issue. The following sub-section clarifies Mode Intentionalism.

\footnotetext{
12 Crane originally describes Mode Intentionalism as 'Strong Intentionalism', contrasting it with 'Strong Representationalism', and later switches to 'Impure Intentionalism', contrasting this with 'Pure Intentionalism' (see respectively, Crane 2001, 2009a: 474-493; see also Chalmers 2004: 155). The latter contrast tracks my distinction between Strong Intentionalism and Mode Intentionalism. Ultimately the labels are not particularly important, as long as the differences are kept in mind. However, calling the view 'Mode Intentionalism' puts the distinctive claim that intentional modes contribute to determining the phenomenal character of intentional experience at the forefront-so there is justification for the labels I have adopted.

13 See Dretske (2000), Tye (1995) and Harman (1990: 31-52).
} 


\subsection{Clarifying Mode Intentionalism}

First, we need to get clearer on intentional modes. Those advocating Mode Intentionalism typically specify them in terms of determinate types of experience. ${ }^{14}$ Importantly then, intentional modes should not be confused with modes of presentation which are one way of theorising the aspectual dimension of intentional content (see Sect. 3.1). For informative purposes, consider the propositional attitudes. Thought per se, is a determinable, of which determinate attitudes are judging, hoping, wishing, wondering, expecting, etc. Simplifying, these are all transitive attitude verbs, which take (propositional) contents as sentential complements (e.g. judging that $\mathrm{P}$, hoping that $\mathrm{P}$ ). As such, we have a range of different propositional attitudes, which (on standard views) relate us to propositional contents. We can, therefore, make a distinction between the attitude and the content.

It might similarly be suggested that sense-perceptual experience, or perceiving based on the senses, is a determinable, of which the determinate modes are (at least) vision, hearing, taste, smell, and touch-although paradigmatic sensory experience is multimodal. The distinctive claim of Mode Intentionalism is that what determines the phenomenal character of an intentional experience is both that it has the manifest content it does and that it is the relevant type of experience it is-that it is in this intentional mode, rather than a different one. For example, what determines the phenomenal character of a visual experience is both the manifest content - the intentional object under the relevant aspect(s) - and that it is a visual experience. ${ }^{15}$

However, Mode Intentionalism requires further clarification to avoid being a form of Strong Intentionalism. It must hold that the intentional mode is phenomenologically manifest. ${ }^{16}$ To make this clear, let me approach this issue from the angle of intentional individuation. Given the minimal commitments of Intentionalist views, the manifest content of an intentional experience will have a central role in individuating the relevant mental state- that is in making it the experience it is and differentiating it from others. For Strong Intentionalism that role is exhaustive: once we have fully specified the manifest content, there is no more that needs to be done to pick out the intentional experience as the experience it is. Mode Intentionalism disagrees. What individuates an intentional experience is both that it has the manifest content it does and that it is in the intentional mode it is.

But if intentional individuation of this kind is to capture how things are from the subject's perspective, such that the criteria for individuation should be available to

\footnotetext{
${ }^{14}$ See Crane (2000: 1-11, 2001: 139, 2009a: 474-491). See also Searle (1983: 4-6, 12, 1992: 129-132) and Chalmers (2004) calls this feature the 'manner of representation' of the experience, and Husserl (2001) calls it 'act-quality'.

15 There is the further claim made by Crane that the structure of intentional states is relational, insofar as one is related to an intentional content on the basis of the relevant mode (see Crane 2001: 28-33, 2003: 7-11; cf. Searle 1983: Ch.1). This turns on issues concerning what to say about non-existent objects so need not concern us here.

${ }^{16}$ Crane commits to this (see 2000: 8; 2001: 144) as does Chalmers (2004: 176-178). Note the notion of something being phenomenologically manifest is broad enough to allow that it might be part of the background of the experience, or figure in a non-prominent way. I thank a referee at Erkenntnis for pressing me on this point.
} 
the subject undergoing the experience, then intentional individuation in this context is phenomenal intentional individuation. It is a kind of individuation the grounds for which are phenomenal. ${ }^{17}$ Insofar as we have framed content as manifest content, then that is available to the subject, as something within their ken which (at least partly) captures how things are experientially with them. However, if intentional modes are to contribute to phenomenally individuating intentional experience, then the relevant modes would have to be phenomenologically manifest. Put otherwise, if the relevant intentional mode was not in some sense given within the first-person perspective to phenomenal consciousness, then it couldn't be part of the phenomenal grounds for individuating the relevant intentional experience.

Given this clarification, we should distinguish between phenomenal and non-phenomenal Mode Intentionalism. The former is the view that the intentional mode of the experience is phenomenologically manifest, so contributing to the phenomenal character of the experience and supporting phenomenal intentional individuation. The latter view might claim that intentional modes are theoretical categories. We introduce them in theory of intentionality to play a classifying role, but they are not the kind of thing that is phenomenologically manifest. ${ }^{18}$ Simply put: Intentional modes qua intentional modes are not part of the first-person phenomenal character of intentional experience. But if that is the case, then intentional mode qua intentional mode cannot be something which partly determines the phenomenal character of intentional experience (or supports phenomenal intentional individuation). Nonexperiential reflective categorizations of experience types are not the kind of thing that determines the phenomenal character of intentional experience. Instead, they are the type of thing that is supposed to (conceptually) reflect phenomenal character. So, non-phenomenal Mode Intentionalism is just a version of Strong Intentionalism when it comes to answering the question of what it is about experience that determines what-it-is-like. Given this, let's continue to talk of Mode Intentionalism, keeping in mind that we are talking about phenomenal Mode-Intentionalism.

Let me now explain how Mode Intentionalism should not attempt to make intentional modes phenomenologically manifest by placing them into the manifest content. This kind of view would have it that the structure of intentional experience is as follows: there is the 'primary' intentional object, under the relevant aspect, and a 'secondary' intentional object, the mode of the experience, which would be presented under a certain aspect. Take my visual experience of a vista. There is the primary intentional object, the vista, which is presented under the relevant aspects, say as having certain colour and spatial properties. In addition, there is the secondary intentional object, the mode of experience, presented under the aspect of being visual. Therefore, the content would involve both. It might be suggested that such a view would hardly be Mode Intentionalism since intentional modes become part

\footnotetext{
17 One can individuate intentional states in non-phenomenal and non-intentional ways. For example, in terms of their causal-functional role, or the neurophysiological state on which they are based. Alternatively, one might individuate them in terms of externalist representational content, which need not be phenomenally manifest to the subject undergoing the experience.

18 Arguably this is closer to Searle's $(1983: 4-6,12)$ view.
} 
of the manifest content. That is a fair complaint, but explaining why this strategy is problematic is instructive.

There is the threat of an infinite regress. If the intentional mode is phenomenologically manifest in virtue of the experience also being secondarily directed toward it, then we might ask what the intentional mode of this second form of directedness is and whether it is phenomenologically manifest in virtue of being taken as an object. The view cannot respond that there need be no intentional mode under which the intentional mode (second-order) is experienced since we would need a principled reason for why intentional modes are not required for second-order representations whereas they are for first-order representations. Perhaps the more cogent response is that intentional experience necessarily includes higher-order thoughts which take intentional modes as secondary intentional objects and that the intentional mode of thought need not be phenomenologically manifest (i.e. is unconscious). However, even if the regress can be stopped in this way, we are led to the following further problem.

There is an important distinction between the fact that one's experience is a visual experience, and the intentional mode being phenomenologically manifest in anything like the way the 'primary' intentional object is. In this context, we might appeal to the distinction between phenomenal or sensible awareness of objects and their properties, and fact-awareness that such and such is the case. ${ }^{19}$ An example of the former is my visual awareness of the vista and its properties, of the latter that my experience is a certain type.

Whatever intentional modes as purportedly phenomenologically manifest components of experience are, they are not the kind of thing which figure in experience by way of phenomenal or sensible object-awareness. For example, in having a visual experience I don't—in addition to seeing the vista and its properties-simultaneously seem to see or otherwise sense (at least on any standard understanding of those terms) the intentional mode of the experience (and its properties). To flesh out this phenomenological claim, consider that the mode of my experience, say its' being a visual experience, doesn't seem to be located anywhere in my field of vision. Further to this, it doesn't seem to figure as something I can visually attend to in the way I can visually attend to the vista and its properties, and it certainly doesn't look a certain way.

Supporting these phenomenological claims, intentional modes don't meet one of Sydney Shoemaker's criteria for object-perception, namely a kind of (re)identification condition. As he puts it, "when one perceives one is able to pick out one object from others, distinguishing it from the others by information, provided by the perception, about both its relational and its nonrelational properties. The provision of such information is involved in the "tracking" of the object over time, and its reidentification from one time to another' ${ }^{20}$ Yet, intentional modes (as putatively

\footnotetext{
19 See Dretske (1999: 39-65) and Shoemaker (1996: 5, 205).

20 See Shoemaker (1996: 205). Shoemaker presents these considerations in the context of an argument concerning introspection, specifically arguing for the conclusion that we do not have a special sense for detecting our own experiences.
} 
manifest in experience) don't seem to be the kind of thing one identifies by distinguishing their (relational and nonrelational) properties. And the idea that senseperpetual experience provides one with information about intentional modes as a means to re-identify such modes on different instances by virtue of involving a kind of object-perception of them sounds odd. Such considerations sufficiently support the claim that however intentional modes figure in experience they are not perceived or sensed, or at least not in a way that can be modelled after the object-perception involved in sense-perceptual experience.

On the other hand, if the way intentional modes are phenomenologically manifest is on the basis of a co-present accompanying fact-awareness, then all intentional experiences would involve higher-order thoughts with conceptual content. This is because such fact-awareness that one's experience is in the relevant mode would require higher-order thoughts with the conceptual content that $<$ my experience is a mode (e.g. visual) experience $>$. The subject whose experience involved such fact-awareness would have to meet the possession conditions for such concepts as EXPERIENCE and VISUAL. This is cognitively over-demanding: Intentional experience would necessarily involve higher-order cognitive-conceptual states concerning intentional modes. ${ }^{21}$

Summing up, for Mode Intentionalism to be a distinctive proposal about what determines the phenomenal character of intentional experience the following must be the case. First, the relevant intentional mode must be phenomenologically manifest qua intentional mode, rather than as a non-phenomenal theoretical category. Second, and relatedly, it shouldn't be the case that this is achieved by placing intentional modes into the manifest content on the model of either phenomenal or sensible object-awareness, or fact-awareness.

Before considering the phenomenal contrast argument for Mode Intentionalism let me again note the availability of the view I called Intentionalism about Mode since it is arguably a view which makes intentional modes phenomenologically manifest by building the mode into the content (as a kind of mode-infused content). The mode would figure in a separate content-based aspect of the experience-yet presumably, given the considerations above, not on the model of either objectawareness or fact-awareness. We will have occasion to consider this view in detail in Sect. 5. The argument that follows focuses on Mode Intentionalism.

\section{The Phenomenal Contrast Argument}

\subsection{The Form of Argument}

Here is the central argument one finds for Mode Intentionalism. ${ }^{22}$

\footnotetext{
${ }^{21}$ Cf. Higher-Order-Thought theories of consciousness which come close to the first part of this claim (see Rosenthal 1986: 329-359).

${ }^{22}$ See Crane (2000: 8, 2001: 86, 2009a: 474-491), Horgan and Tienson (2002: 520-33). Block (1996: 38) also uses cross-modal cases to argue against Strong Intentionalism (see fn. 25).
} 


\section{Arg.1 The Phenomenal Contrast Argument}

$\mathrm{P} 1$. It is possible to have pairs of intentional experiences which share the same manifest content but differ in phenomenal character.

$\mathrm{P} 2$. The best explanation of such a phenomenal difference is that there is a difference in the relevant intentional mode.

C. Mode Intentionalism is true: there are phenomenal differences that aren't manifest content differences but are differences in intentional mode.

Let me first say something about the argument form. We have an argument from the best explanation, and so it is abductive rather than deductive. To ultimately make good on the claim that Mode Intentionalism is the best explanation of the truth of P1 (if P1 is true-see below) we would have to consider alternative explanations (i.e. alternative Intentionalist views). Importantly if P1 is true, then Strong Intentionalism is false, and so would not be an alternative explanation for P1 being true. The central alternative is Weak Intentionalism (although the abductive form leaves this open). As promised, I won't comment on the plausibility of Weak Intentionalism. However, to ultimately make good on this argument Weak Intentionalism would need to be shown either (1) false on independent grounds, and so not a possible alternative explanation, or (2) in some way a less good explanation than appeal to intentional modes making the relevant phenomenal difference. With this clarified, I bracket this issue. ${ }^{23}$

A further issue with the argument is that P1 begs the question against Strong Intentionalism: Strong Intentionalism claims that all phenomenal differences are differences in manifest content and P1 denies this. However, this is fine if P1 can be shown true by reference to phenomenal contrast cases, and so Strong Intentionalism false, although this needs demonstrating, not assuming. In what follows, I consider cases that purport to show that P1 is true (so from which P2 follows given what we are assuming above).

As a final comment on the argument let me emphasize why (1) it is helpful to formulate phenomenal contrast cases in arguing for Mode Intentionalism, and (2) the view needs to find cases in which it is prima facie plausible that the manifest content is the same across pairs of experiences (as supporting P1). Concerning (1), note that if one were to consider a single intentional experience, not engaging in any comparison, it would be difficult to determine what aspects of phenomenal character to attribute to manifest content versus intentional mode. Intuitions clash about whether intentional modes are required to explain phenomenal character in any given case: Mode Intentionalism insists they are, Strong Intentionalism denies this. By considering phenomenal contrast cases, we have something against which to test these views, since there is a data point (the phenomenal contrast) which requires explanation, and we can assess the plausibility of different explanations.

Concerning (2), remember that Mode Intentionalism, as a form of Intentionalism, accepts that differences in manifest content make differences to phenomenal character. So, there will be all manner of phenomenal contrasts between different

${ }^{23}$ Intentionalism about Mode would be another option; see Sect. 5. 
experiences that Mode Intentionalism will agree depend (in part) on differences in manifest content. The Mode Intentionalist will add that, nonetheless, the relevant intentional mode also contributes to phenomenal character. However, where manifest content is also a variable, it will be difficult to assess whether phenomenal contrasts across pairs of experiences support an appeal to a phenomenologically manifest intentional mode or can just be captured in terms of those differences in manifest content. So, the Mode Intentionalist needs to find special cases of phenomenal contrast in which it is prima facie plausible that the manifest content is the same across pairs of experiences. It is then up to the Strong Intentionalist to defeat any such prima facie plausibility.

Now that we have seen why Arg. 1 takes the form it does we can consider cases which purport to show that P1 is true.

\subsection{Three Examples}

Here are three examples of phenomenal contrast cases for sense-perceptual experience.

Example 1 Visual and tactile

In the 1970s a water-based covering called Artex was used to decorate ceilings, using swirling effects to produce a textured finish. As it happens, I'm in a room with an Artex ceiling. Looking up at a portion of the ceiling, I enjoy a visual experience which presents it as looking rough, and so which has the manifest content <ceiling as rough> (granting roughness is a property that can be presented in visual experience). Intrigued by the rough look of the ceiling, I investigate further, reaching up to touch it. This time I enjoy a tactile experience which presents the same portion of the ceiling as feeling rough, and so which also has the manifest content <ceiling as rough $>$.

Example 2 Visual and interoceptive

A patient is rushed to hospital with spinal cord compression of the kind which leads to numbness in the lower half of the body. Laid out on the hospital bed, the doctor checks for sensitivity in the patient's legs by pricking a needle into their foot. The patient visually observes the doctor's action, and so has a visual experience with the manifest content $<$ foot as pin-pricked $>$. However, they feel no sensation. The patient is rushed to surgery to remove a herniated disc which is compressing the sciatic nerve. Sometime after the surgery, the doctor returns to check the sensitivity in the lower half of the patient's body, carrying out the same observation by pricking a needle into the same spot on the patient's foot. The surgery was a success, and the patient now feels the pin-prick, and enjoys an interoceptive experience with the manifest content $<$ foot as pin-pricked $>$. 
Example 3 Taste and smell

Sitting in a restaurant perusing the menu, I opt for the seabass. Unbeknownst to me, the fillets are past their sell-by-date. The waiter brings the dish, and I can smell that the fish is rotten; I have an olfactory experience with the manifest content $<$ fish as rotten $>$. However, I want to make sure, so I take a small bite. Unfortunately, my suspicions are confirmed since it also tastes rotten. And so, I have a gustatory experience with the manifest content $<$ fish as rotten $>$.

In all three examples, we have a pair of experiences in which it is prima facie plausible that the manifest content is the same. But there is a phenomenal contrastsubstantiating P1 in Arg. $1 .^{24}$ There is a phenomenological difference between whatit-is-like to see the ceiling as rough from what-it-is-like to feel the ceiling as rough; between what-it-is-like to see one's foot being pin-pricked from what-it-is-like to (interoceptively) feel one's foot being pin-pricked; and finally, between what-it-islike to smell the fish as rotten from what-it-is-like to taste the fish as rotten.

Given that we accept this, we need an explanation of the phenomenal contrast. Absent a possible appeal to manifest content-which is the same across the pairs of experiences - the best explanation is that they are in different phenomenologically manifest intentional modes. In Example 1, the first is in the visual mode, whereas the second is in the tactile mode. In Example 2, the first is in the visual mode, whereas the second is in the interoceptive mode. In Example 3, the first is in the mode of smell, whereas the second is in the mode of taste. And this makes a phenomenological difference that outruns the manifest content of those experiences. ${ }^{25}$

However, the sameness of content claims in these cases is arguably defeated by the following line of thought. Michael Tye considers an example in which one imagines the difference between seeing a round shape and feeling the same shape by running one's fingers over it: 'Suppose that in both cases, one has an experience as of a round shape. Still, the one is a haptic experience and the other a visual experience. Phenomenologically, there is a significant difference between the two... ${ }^{26}$ So, if the content of these experiences is nothing more than $<0$ is round $>$, then the phenomenal contrast argument for Mode Intentionalism goes through.

However, the Strong Intentionalist can reply that there is more to the content of both experiences, with respect to which they are different: 'in seeing the shape one has an experience as of colour. But, colour is not represented in the content of the haptic experience. Conversely, temperature is represented in the haptic experience

\footnotetext{
24 Note that in Example 3 the experiences involve high-level content, and this could also be said of Example 2 [see Siegel (2010) for discussion of high-level content; see also fn. 28].

25 Block (1996: 38) gives an example of a non-content based phenomenal contrast between a visual and auditory experience of an aeroplane having the same perceived location-both having the content 'as of that location'. This is not compelling for reasons given by Tye (2000: 94-95), and because the way visual experience locates its object in space is more precise than the way auditory experience does. Given this, it is not clear that the demonstrative fixes on the same location.

26 Tye (2000: 94-95).
} 
but not in the visual one (or at least not to the same extent) ${ }^{27}$ The thought is that the overall contents of the experiences outstrip the mere representation of the shape as round, and it is these other differences in content that can be recruited to explain the phenomenological differences pace Mode Intentionalism.

Let me say several things about this response. First, it is possible to imagine creatures whose visual experiences don't include experiences of the colours of the shapes they perceive. Indeed, those with total colour-blindness (say of the cone monochromacy type), only see things in greyscale. Likewise, it is possible to imagine creatures who enjoy forms of haptic perception in which temperature is not represented. In considering such cases, we wouldn't-as Tye claims-be engaging in a suspect process of mental abstraction from actual experiences. Instead we would imagine possible experiences that in critical respects have less content than paradigmatic cases. If that is the case, then the Mode Intentionalist can place (idealised) restrictions on the examples to insulate them from this response.

Second, consider the following point. Those intuitive phenomenal differences between the contrasting experiences don't seem to turn on additional properties being represented that were simply not mentioned in the original descriptions. Put otherwise, the phenomenal differences that seem pre-theoretically obvious connect to those experiences qua their being visual experiences of texture versus haptic experiences of texture (Example 1). This is not to deny that if the visual experience also represents a colour property, this will make a phenomenal difference. The critical question is whether it makes the relevant phenomenal difference which is intuitive in the original description. As such, arguably the phenomenal difference between what-it-is-like to see the ceiling as rough versus feel the ceiling as rough requires an explanation which turns on differences connected to visual experiences of roughness versus haptic experiences of roughness. The fact that such experiences may represent other properties as well doesn't hone in on this desideratum.

So, in what follows I show why Arg.1 fails in a way which grants that there is a prima facie plausibility to sameness of content claims in such cases qua the 'central' properties putatively represented (as the properties focused on in the original examples).

\section{The Strong Intentionalist Critique}

In the previous section, we saw that Mode Intentionalism appeals to examples which provide reason to think that P1 in Arg.1 is true. I now consider responses from the Strong Intentionalist, who resists any appeal to phenomenologically manifest intentional modes determining (even if only in part) the phenomenal character of experience.

Here is the chief strategy the Strong Intentionalist should adopt. In Examples 1, 2 , and 3 , the properties experientially represented are, on closer examination, phenomenally different. As apparent properties of the ceiling, roughness-felt is not

27 Ibid: 95 . 
experientially exactly the same property as roughness-seen. Likewise, as apparent properties of my foot, pinprick-felt is not experientially exactly the same property as pinprick-seen. And finally, as an apparent property of the fish, rottenness-smelt is not experientially exactly the same property as rottenness-tasted. Let me parse this in more philosophical terms. ${ }^{28}$

It may be the case that the object and its properties refer to the same real object, as a concrete physical particular, and properties that it in fact has. In veridical cases this object (and its properties) would stand in a causal relation to experience, so determining the same wide (externalist) representational content. So, perhaps the pairs of experiences have exactly the same content in that sense of content (i.e. same property-referents).

Remember though, Strong Intentionalism need not be committed to this. Instead, what is crucial for determining whether manifest content is exactly the same across pairs of experiences is whether those experiences have the same property-senses. At the most general level, property-senses can be characterized as the way the relevant property seems to the subject. So, the property-sense of the colour red would be intentionally individuated in terms of the property that looks the way red looks. As such, we are appealing to a notion of sense-individuated properties. These are properties intentionally individuated at the level of how the relevant property of the intentional object seems. Therefore, we a considering how that intentional object is given under a specific mode of presentation.

However, the above formulation of property-senses is not as precise as one would like. What is evident is that property-senses are properties that are tied to the way things appear. However, it might be asked, which properties? There are many candidates. For example, for an arbitrary property F, F's property-senses could be:

(1) The properties that correspond to, but are not identical with, the properties that $\mathrm{F}$ things appear to have.

(2) The properties that $F$ things appear to have.

(3) The properties that $F$ things appear to have to certain subjects.

(4) The properties that F things appear to have to certain subjects under standard conditions.

(5) A proper subset of the properties that $F$ things appear to have to certain subjects under standard conditions.

In this sense, merely saying that F's property-senses are individuated by how $\mathrm{F}$ seems to a subject doesn't decide between these characterizations. Going forward,

\footnotetext{
28 A different strategy is to insist that roughness, for example, isn't ever visually represented, and is only a proper sensible of touch, and therefore not a common sensible which it is possible to be presented with across sense-modalities (see Dretske 2000: 158-177; cf. Crane 2001: 86). While this might be a plausible route for the Strong Intentionalist to take in some cases, in essence denying there are any common sensibles, the strategy would have to be amended for Examples 2 and 3. One option in those cases would be to deny that sense-perceptual experiences have the relevant kind of high-level content (e.g. rottenness is not a proper sensible at $\mathrm{all}$ ). However, such a move strikes me as unpersuasive for cases like Example 4 (see Sect. 4).
} 
let's operate with (4); property-senses are the properties that $F$ things appear to have to certain subjects under standard conditions. So, the property-sense of the colour red would be the property that red things appear to have to a certain subject under standard conditions (e.g. standard lighting conditions).

Returning to the central dialectic, let me illustrate the importance of this distinction between property-referents and property-senses. A familiar claim of Intentionalist views is that it is possible to undergo hallucinatory experiences that are phenomenally indistinguishable from their veridical counterparts. ${ }^{29}$ For example, it is possible to enjoy a hallucinatory visual experience as of a red and rectangular table that would be phenomenally indistinguishable ('from the inside') from a veridical experience-a factive seeing of a red and rectangular table.

Do the experiences have the same content? It depends on our notion of content. The two experiences differ in their wide (externalist) representational content, insofar as this is understood as what is determined by causal relations to the environment. The veridical experience is relational in this sense, whereas the hallucinatory experience ex hypothesi isn't. Although the subject (putatively) couldn't tell, just based on the experience, whether they were in the 'good case' or the 'bad case'. However, what is the same, according to the Intentionalist views under consideration, is the manifest content as specified in terms of the sense-individuated properties. Both involve the same property-senses, such that the subject is being appeared to in the same way. In both the veridical and hallucinatory perceptual experience, the red and rectangular table appears to have the properties that red and rectangular tables appear to have to the relevant subjects under standard conditions.

The flip side is that two experiences may 'represent' the same reference-individuated properties - the relevant properties being, in fact, the same-but leave it open whether those experiences 'present' the same sense-individuated properties to the subject. Indeed, in our ceiling case, this is true. The physical-chemical composition of the Artex, which in veridical cases causes both its visual and tactile appearance, is the same. Likewise, in our rotten fish case: the physical-chemical composition of the fish, which in veridical cases causes both its smell and taste is the same (typically it is the presence of a specific organic compound called trimethylamine). However, it doesn't follow from this that the sense-individuated properties across the cases are the same.

Given this analysis, the Strong Intentionalist has a way of respecting the phenomenal contrast between the pairs of experiences in our examples. Simply put: The Strong Intentionalist can appeal to the sense-reference distinction, with phenomenal character determined by content understood (at least in part) at the level of sense, and more specifically in terms of property-senses. They can say that the phenomenally contrasting cases experientially present different sense-individuated properties of the same intentional objects, and so have different overall manifest contents (regardless of whether they share the same wide content). Or in different terminology, the pairs of experiences have different (overall) sensible profiles. And it is

29 Naïve realist views deny a version of this claim (e.g. Brewer 2011). 
accepted that difference in sense (so understood) guarantees a difference in phenomenology for experiential states. ${ }^{30}$

We can now present an argument which formalises this analysis and undermines Mode Intentionalism.

\section{Arg.2 Against Mode Intentionalism}

P1. Two intentional experiences which share the exact same manifest content would share the same property-sense.

$\mathrm{P} 2$. Difference in property-senses across experiences guarantees a difference in phenomenal character.

P3. Insofar as we have a pair of experiences which are directed toward the same intentional object in which there is a phenomenal contrast, then it is legitimate to ask whether the property-senses are the same.

$\mathrm{P} 4$. In the relevant phenomenal contrast cases offered by Mode Intentionalism, the property-senses are in fact different, and so a difference in property-sense (and so manifest content) is available as an explanation of the phenomenal contrast.

(C) Mode Intentionalism is not well-motivated by the relevant phenomenal contrast cases.

Applying this argument to our pairs of experiences, consider Example 1. There is undoubtedly a phenomenal contrast between the two experiences. But it is questionable whether the manifest content is exactly the same qua property-sense. While we may misleadingly use the same word for the properties in play-namely 'roughness' - the sensible profiles are arguably different. Likewise, for Example 3. Anyone who has ever smelt rotten fish knows that it smells significantly worse than it tastes, and the taste of rottenness is different from the smell of rottenness. For example, rotten meat usually has a sweet aspect, which isn't part of the smell of rotten meat. More could be said about the relevant property contrasts here. But it seems reasonable to suppose that (as in Example 1) while we may misleadingly use the same word for the properties in play_namely 'rottenness' — the sensible profiles are manifestly

\footnotetext{
30 See Johnston (2004: 134-135) and Chalmers (2004: 171-177) (cf. Speaks 2009: 545-553; Shoemaker 1996: 104). A similar strategy is deployed by Tye (1995: 155-159, 2014: 47-48) and Bain (2003): 517-518. Chalmers (2006) tries to capture a similar notion of property-senses with his notion of Edenic properties. Let me, however, note a worry. It might be said we need a more robust way of individuating property-senses than merely by appeal to the properties that $F$ things appear to have to certain subjects under standard conditions. After all, this might be read as claiming that we are individuating propertysenses (at least partly) on the basis of phenomenal character, and so helping ourselves to the very thing the Strong Intentionalist hopes to explain: how to individuate content in such a way that it entails individuation in phenomenal character. Put otherwise, if we are using phenomenal character-how the relevant property phenomenally seems - to decide when distinct properties are represented, then arguably we can't then turn around and say that the representations explain the phenomenal character. For this paper, I don't wish to provide an extensive defence of Strong Intentionalist on this issue. However, note that the Strong Intentionalist might reply that we should further individuate property-senses by their internal causal/functional roles (see Chalmers 2004: 171-177). More needs to be said on this issue (although see the point in the text below concerning the connection between differences in sensible profile and connection to belief contexts).
} 
different (ditto for Example 2). ${ }^{31}$ Yet, if the sensible profiles are different, we don't need to appeal to differences in phenomenologically manifest intentional modes to explain the phenomenal contrasts, we can just appeal to differences in manifest content.

To further support P4 (in Arg.2), consider the following points. One feature of intensional contexts for linguistic expressions, in which the same referents are presented under different senses, is the failure of substitution of co-referring terms for the relevant inferences. Mapping analogous considerations onto experiences, it is relatively non-controversial that if two experiences have different manifest contents, such that their sensible profiles differ, then this should be reflected in a difference in which beliefs it is rationally acceptable for subjects to form (and hold) on their basis. ${ }^{32}$ From this we can generate the following constraint: If a pair of experiences, directed toward the same object, differ in their sensible profiles then it is rational for a subject to believe that one and the same object is the way it is presented in one experience and at the same time not believe (or withhold assent to believing) that the object is the way it is presented in an alternative experience they haven't had.

With this constraint in mind, consider a modification to Example 1. Say I have the visual experience of the ceiling as looking rough, but I don't touch it. It is rationally acceptable for me to assent to the belief that the ceiling looks rough while withholding assent to whether the ceiling feels rough. I may guess; 'things that look rough usually feel rough'. But this is irrelevant; if the property-senses (and so manifest content) were exactly the same, there would be no need for guessing. I would be (seemingly) acquainted with roughness per se, as a common sensible. If the sensible profiles were exactly the same-as Mode Intentionalism needs them to be to substantiate P1 in Arg.1-then, other things being equal, there would be no disanalogy in terms of the beliefs it would be rationally acceptable to hold. But there is. And it is the difference in sensible profiles which would explain why it is rationally acceptable for me to take myself to be in a good epistemic position to judge that the ceiling looks rough without ipso facto committing to its feeling rough. There is no rational failing here because I don't have (seeming) acquaintance with the intentional object under this different sensible profile, as having that property-sense.

Summing up, it remains open for the critic of Mode Intentionalism to argue as follows concerning the examples in Sect. 2.2. The different pairs of experiences present the same intentional objects as having different property-senses-as having different overall sensible profiles. As such, they don't have exactly the same manifest content. If that is correct, then we have not been given cases which conclusively show that P1 in Arg. 1 is true and so the argument doesn't go through. ${ }^{33}$

\footnotetext{
31 See Bain (2003: 17-20) on the distinct sensible profiles involved in visual and interoceptive experience. Bain makes the claim (following Martin 1998b: 269-270; 1993: 209-210) that the difference in content in such cases is partly to be explained in terms of the object of the interoceptive experience (in contrast to the visual case) presenting as oneself, and so as including a sense of bodily ownership.

32 See Evans (1982) and Peacocke (1992).

${ }^{33}$ Let me address a worry about the notion of content as involving property-senses. One might argue that the notion invoked is merely a subjective difference in the mode of access to the object, in that it does not even purport to represent objectively different entities in the world. But if that is the case, it might be asked why such differences in property-senses that are 'merely subjective' are not merely phe-
} 


\section{Unsuccessful Mode Intentionalist Responses}

The Mode Intentionalist might respond to the argument of the previous section as follows. They could claim that the Strong Intentionalist makes use of intentional modes in talk of seen-roughness and felt-roughness (or smelt-rottenness and tastedrottenness). Furthermore, if roughness can only be experienced with property-sense $A$ via vision and property-sense $B$ via touch, and property-senses determine phenomenal character, then this version of Strong Intentionalism is arguably just a notational variant of the claim that the visual and tactile modes partly determine phenomenal character. So, despite the hyphens, the italicised terms refer to intentional modes, and given that, they are contributing to phenomenal character in a phenomenologically manifest way.

If this is the case, it might be questioned what the rationale is for thinking of these different property-senses as differences in content rather than mode, given that our expressions for them are associated with the relevant modes. Furthermore, why is it still important that we are to count such differences in property-sense as differences in content rather than mode? ${ }^{34}$

Let me explain why this line of response is unconvincing and answer these questions. First, the Strong Intentionalist can emphasize that given their fine-grained character, it is difficult to capture the relevant sensible profiles-as marking the differences in manifest contents-in words. Our linguistic competence for expressing the phenomenological difference in property-senses between roughness-felt and roughness-seen is limited. Perhaps talk of 'seen-roughness' and 'felt-roughness' is as good as it gets without engaging in detailed comparative descriptions (e.g. seenroughness is a property-sense which is like this, whereas felt-roughness is a property-sense which is like this etc.). As such, these phrases are shorthand for roughness as a property-sense when I see it, and roughness as a property-sense when I feel it (ditto for felt-pinprick vs seen-pinprick in Example 2 and smelt-rottenness vs tasted-rottenness in Example 3).

Once so explicated, the Strong Intentionalist incurs no commitment, at least in virtue of the use of such abbreviations, to intentional modes as phenomenologically

\footnotetext{
Footnote 33 (continued)

nomenal? Put otherwise, is there a substantive difference between this kind of view (which one might call aspectual-shape intentionalism) and a view which would count such differences as "purely phenomenal'? First, to repeat, the notion of property sense is as follows: Property-senses are the properties that $F$ things appear to have to certain subjects under standard conditions. So, concerning the experiences themselves, such property-senses do purport to be properties of objective entities in the world (as the sensible profiles of apparent objects). Such differences in property-senses therefore will not seem 'purely phenomenal' insofar as they appear to the subject as differences in the way the object of the experience seems. Whether such property-senses should be metaphysically counted as no more than 'purely phenomenal' differences, in the sense of lacking genuine reference (i.e. picking out a metaphysically real property), taps in issues which I am not considering in this paper (see Introduction). Nonetheless, there is an important difference between Strong Intentionalism qua content involving property-senses, and a view where such property-senses are 'purely phenomenal' in the sense of not even seeming to be appearance properties of objects. I thank a referee at Erkenntnis for pushing me to clarify this issue.

${ }^{34}$ I thank a referee at Erkenntnis for pressing me to sharpen this response.
} 
manifest components of experiences, as something different and separate from the relevant intentional content, so understood. Put otherwise, there is nothing in the notion of property-senses as explicated in the previous section that commits one to the claim that phenomenal character outruns manifest content.

Second, the Strong Intentionalist can emphasize that when it comes to the theory of intentionality talk of different intentional modes is fine. We intelligibly theorize about categorical differences between vision, touch, audition, gustation, olfaction, interoception, etc. But when it comes to what determines phenomenal character, differences across pairs of experiences in phenomenal contrast cases are always differences in manifest content by way of property-senses. In this sense, it remains open for the Strong Intentionalist to claim that paradigmatic sense-perceptual experiences are mode transparent: intentional mode qua intentional mode is not a manifest part of the phenomenal character of those experiences - it is not a part of how things are experientially for one in the way required by Mode Intentionalism (and the phenomenal contrast cases considered do not show otherwise). In that sense, it remains important for the Strong Intentionalist that we count such differences in propertysenses as differences in content rather than in mode to accurately reflect the claimed phenomenology of mode-transparency.

Given these points, the Strong Intentionalist position that, for example, roughness can only be experienced with property-sense $A$ via vision and property-sense $B$ via touch, and that phenomenal character is determined by these property-senses, does not become a notational variant of Mode Intentionalism. Intentional modes are still not phenomenologically manifest qua intentional modes on this version of Strong Intentionalism, and the truth of that latter claim is essential to Mode Intentionalism.

However, the Mode Intentionalist can take a different tack by asking what grounds the reflective judgement that my experience is a visual experience. They might press the following point: If it were not the case that before reflection the intentional mode is a phenomenologically manifest aspect of my experience, then I would have no grounds for making the typically correct reflective judgement that my experience is in the relevant mode. Given we make such correct judgements, the best explanation is that intentional modes are phenomenologically manifest aspects of intentional experience which partly determine its phenomenal character.

The Strong Intentionalist can respond as follows. Arguably this ability can be sufficiently grounded in the kinds of properties (as property-senses) involved in the experience. Consider the visual case. My ability to correctly judge that my experience is a visual experience can arguably be sufficiently grounded in my experience presenting properties that are categorially visual or otherwise observable properties, as having the relevant visual sensible profiles or property-senses. I can know my experience is a visual one and can make that judgement because the properties it presents are the proper sensibles of vision. Note, given this response, the Strong Intentionalist is committed (as one would expect) to those property-senses of 'seen-roughness' and 'felt-roughness' being proper sensibles of vision and touch respectively.

Tying back to issues of intentional individuation the Strong Intentionalist would say the following: To be able to reflectively pick out my experience as a visual experience, and in reflection differentiate it (qua mode) from others, 
requires no more than a recognition that the kind of properties it presents are visual (and only visual) properties. As such, the phenomenal grounds of this ability can be sufficiently captured in terms of the kinds of properties (visual, tactile, auditory, etc.) which figure in the manifest content. These properties characterise what-it-is-like to be appeared to (for subjects under standard conditions) in the relevantly distinctive ways. So, there is no simple route to Mode Intentionalism through considering our ability to reflectively categorize intentional states into different modes.

As a final move the Mode Intentionalist might try a different example:

Example 4 Vision and imagistic memory

One summer I take a trip to Paris. During my stay, I visit the Eiffel Tower taking in its off-brown, slightly gold-tinged metallic colour. I have a visual experience of the Eiffel Tower looking a certain way, and therefore my experience has the manifest content <Eiffel Tower as that colour $>$. At a later date, having returned home, I recollect how the Eiffel Tower looked by visualizing, in imagistic memory, the tower as looking the same certain way it looked when I was there. In doing so, my imagistic experience has the manifest content $<$ Eiffel Tower as that colour $>$.

The Mode Intentionalist might argue that we have a pair of experiences in which the manifest content is the same in terms of the relevant property-sense; namely, the property-sense of the determinate shade 'off-brown, slightly goldtinged metallic', or just 'that colour'. Nonetheless, there is a phenomenal contrast: what-it-is-like to visually see the Eiffel Tower as looking that colour is different from what-it-is-like, in imagistic memory, to recollect its looking that same way. Given the sensible profiles are the same, but there is a phenomenal contrast, the best explanation of that contrast is that the experiences are in phenomenologically manifest different intentional modes (the first visual, the second imagistic memory). If that is correct, we have a case which shows that P1 (in Arg.1) is true and so Arg.1 is running again.

This example is more compelling than Example 1, 2 or 3, qua identical sensible profiles. However, imagistic memory is not a sense-perceptual experience, so we are setting up a phenomenal contrast outside the class of sense-perceptual experiences. However, even bracketing this, it might be said that the manifest content in the visual case would have to reflect the full visual scene, whereas in imagistic memory this would not be (or more strongly could not be) the case. Yet, for the sake of argument, we can grant that either (1) the visual experience can be exclusively focused on the object and its shape and colour, so exhausting its manifest content, or (2) that one could imagistically recollect the full visual scene.

Nevertheless, even granting the above, a set of considerations provides an alternative to the Mode Intentionalist analysis of this example. The alternative claim the Strong Intentionalist needs to show as plausible is as follows: The 
relevant shape and colour property-senses in visual experience seem different, in some important respect, from the relevant shape and colour property-senses as presented in imagistic memory. As such, the manifest content cannot be exactly the same.

Here is one way of substantiating this claim. When in imagistic memory one represents to oneself-in the sense of attempting to again present oneself with-an object as having a specific shape or colour, one's experiential acquaintance with the relevant property-sense lacks something it has when it's a visual property. What it lacks is phenomenal presence, understood as the property-sense seeming to be instantiated, as seeming to really exist now, or in the present. Property-senses, as presented in visual experience, have this feature of phenomenal presence, whereas it is lacking in imagistic memory. Imagistic memory does not present its objects and their properties as seeming to be instantiated, as seeming to really exist now, or in the present, but as existing in the past. They lack phenomenal presence are characterized by phenomenal absence.

Importantly, for the Strong Intentionalist, this distinction needs to be construed as part of the manifest content of those experiences; it needs to be a distinctive aspectual dimension of the sensible profile of visual experiences contrasted with imagistic recollection. What more can be said in defence of this Strong Intentionalist account of the phenomenal presence/absence distinction?

First, note that this distinction is a not matter of a judgement to the effect that the relevant object and its property is present versus absent. Instead, phenomenal presence is something which pertains to experience (likewise for phenomenal absence in the case of imaginative recollection). So, when phenomenal presence is framed as 'the property-sense seeming to be instantiated, as seeming to really exist now or in the present', the seeming is supposed to be a non-cognitive seeming tied to the phenomenal character of sense-perceptual experience.

Granting the above, why we should construe the phenomenal presence/absence distinction as a matter of differences in content, as an aspectual dimension of the experiences rather than something that fixes to the intentional mode ${ }^{35}$ It bears

\footnotetext{
35 An alternative would be as follows. Phenomenal presence can be understood in terms of the (putative) causal self-referentiality of perception, such that sense-perceptual experience involves a causal self-reflexivity which figures as a clause in its content (one might think of this as distinctive 'modecontent', although see Schmitz (2018: 145-6). As Searle puts it 'the visual experience does not represent the causal relation as something existing independently of the experience, but rather part of the experience is the experience of being caused' (1983: 112-140). This analysis might also claim that the phenomenology of imagistic memory involves representing temporal and (earlier) perceptual relations to the remembered event (past causal relations figuring in the content). A general worry about this view is that it potentially undermines the transparency of perceptual experience (see Harman 1990; Tye 2002). If sense-perceptual experience involved a self-referential causal aspect in its content, then this would obstruct the phenomenology of what is experienced as a direct relation (see Soteriou 2000: 173-189). By constructing phenomenal presence as a way the object seems qua 'the property-sense seeming to be instantiated, as seeming to really exist now' we can maintain transparency. Alternatively, as Michael Schmitz (2013, 2017) argues-from an Intentionalism about Mode view-due to differences in the what Searle calls the direction of causation (say between intention and memory) it is questionable whether the relevant intentional states could be said to share contents. See Sect. 5 for a discussion of Intentionalism about Mode.
} 
noting that overall intentional contents are complex. One route to making sense of building phenomenal presence/absence into the content is to say that there can be aspectual qualifications of property-senses in experience (as senses of senses if you will). This might seem profligate, but in contrasting visual experience and imagistic recollection, we arguably come to recognize distinctive aspectual dimensions of content that are, for the most part, passed over simply because they are 'everpresent'. In the case of sense-perceptual experience, the aspectual qualification of property senses as phenomenally present is standard fare. Only in comparison with property-senses as manifest in imagistic recollection do we come to recognize a feature of the content of sense-perceptual experiences which was 'there all along' but takes probing and contrasting to notice.

However, the Mode Intentionalist might respond as follows. Building phenomenal presence into the aspectual shape of manifest content is a complex route to take. Isn't it more plausible to opt for the more straightforward view and say the relevant phenomenal contrast obtains in virtue of a non-content based difference, namely the phenomenologically manifest mode of vision versus that of imagistic memory (as per Mode Intentionalism)?

To see why, despite the apparent complexity, the Strong Intentionalist's gloss on the phenomenal presence versus absence as above has plausibility let me consider a simpler case. Attend to something in your environment that looks red. Shut your eyes and attempt to imagistically recollect the same object as having the same colour. In doing so it is phenomenologically apparent-so the Strong Intentionalist says - that the property imagistically re-presented is aspectually (so contentfully) different from the property as seen.

Here is the phenomenological claim which, therefore, needs to be reflected in the analysis: The relevant colour properties manifestly seem different in the different experiences. Far from having a red after-image of the object as the same float before one's mind, or something approximating a visual hallucination of the same coloured object_ - as merely a different phenomenologically manifest mode of access to what seems like the same property-what we experience is in some sense a 'pale shadow' of it. Hence the idea that imagistic re-presentation of something, even that which is had directly after a visual experience, lacks the vivacity of the original visual experience. At least part of the explanation of why it does, on this view, would be because its content is different qua lacking the phenomenal presence characteristic of (and aspectually qualifying) property-senses as presented in visual experience. Instead, those property-senses are experienced as phenomenally absent. In this sense, the Strong Intentionalist should argue that despite the complexity of the analysis, it reflects something phenomenologically important. Further to this, they would charge the Mode Intentionalist with saying something counter-intuitive. Namely, that it seems like we are presented with exactly the same property, but merely have a different phenomenologically manifest mode of access to it.

Further analysis of the contrast between visual experience and imagistic memory is not possible here. ${ }^{36}$ However, the Strong Intentionalist has grounds for claiming

${ }^{36}$ Cf. Kriegel (2015: 245-276) for a Sartrean account of the contrast which appeals to intentional modes. 
that for two experiences to share exactly the same sensible profiles, then the relevant property-senses would have to share the same aspectual shape qua phenomenal presence versus absence. Insofar as two experiences diverge on this aspectual dimension, then they cannot be said to share exactly the same sensible profiles. So, in Example 4, it is not obvious that when engaging in imagistic recollection what I enjoy is an intentional experience with a phenomenologically manifest different intentional mode, which has exactly the same manifest content as the visual experience of which it is a recollection. Instead, what arguably constitutes the difference between the cases, and putatively explains the phenomenal contrast, is a phenomenologically manifest difference in the overall sensible profiles of the experiences themselves.

At this stage, the Mode Intentionalist might concede the Strong Intentionalist part of the latter's strategy. They could agree that in such phenomenal contrast cases there is always a difference in sensible profiles (and so manifest content). However, they will claim that such a difference can't sufficiently explain the relevant phenomenological differences (even if they are necessary to doing so)—we need phenomenologically manifest intentional modes for that. ${ }^{37}$ But this concession involves abandoning the central aspect of Mode Intentionalism's argumentative strategy (as expressed in Arg.1, specifically in P1) and results in begging the question. Let me explain.

It was said in Sect. 2 that phenomenologically manifest intentional modes (putatively) emerge as well-motivated postulates when considering phenomenal contrasts between pairs of experiences where it is prima facie plausible that the manifest content is the same. Insofar as manifest content is now also a variable across such cases, then it becomes considerably more difficult to substantiate the claim that intentional mode qua intentional mode makes a phenomenological difference. Furthermore, with that aspect of Arg.1 abandoned, we now need a different reason for thinking that a sufficient explanation of the phenomenal difference between contrast cases must include an appeal to a difference in a phenomenologically manifest intentional mode. This cannot be assumed since that claim is just another way of asserting that Mode-Intentionalism is true. As such, the concession can't be made without Arg.1 being abandoned, and so undercutting the motivation for the view.

\section{Intentionalism About Mode}

Before concluding, let me provide reflections on a different approach to these issues, namely Intentionalism about Mode. To remind this reader, this is the view that the relevant mode may not only make a phenomenological difference (phenomenal character being partly determined by mode) but also a difference to the intentional content of experience. In other words, Intentionalism about Mode commits to a special kind of mode-infused content.

\footnotetext{
37 See Crane (2001: 86, 2003: 21-22).
} 
First, let me make a point about the dialectic of the paper. As we have seen, the Strong Intentionalist responses to the Mode Intentionalist consist is explaining phenomenal contrast cases by reference to (subtle) differences in content, where the notion of manifest content is as follows: The object presented, as it presented to the subject under a specific aspect. This notion of content excludes 'mode-infused' content insofar as the latter is ostensibly a kind of content which doesn't concern how the object of the experience is presented (see below). Nonetheless, the argument of the previous two sections, while perhaps sufficient to reject Mode Intentionalism (about sense-perceptual experience), could be thought insufficient (even via negativa) to motivate Strong Intentionalism. Since there may be an alternative explanation of the relevant phenomenal contrasts that does not appeal to (1) differences in manifest content as per Strong Intentionalism, or (2) differences in phenomenologically manifest intentional modes as per Mode Intentionalism, but rather (3) differences in supposed 'mode-infused' content as per Intentionalism about Mode. Given this, it is important to consider Intentionalism about Mode, since that allows for further clarification of whether the relevant phenomenal contrasts might admit of an alternative explanation.

To get more traction, we need to get clearer on mode-infused content. First, it is important to distinguish it from manifest content as defined above, as 'what-content' or 'object-content'- as determining, in the sense-perceptual case, what is perceived. ${ }^{38}$ To make mode-content clearer, consider the following example. A patient suffering from a neurological impairment does not experience certain bodily movements as caused by himself. He often has visual experiences of his limbs moving, but not as caused by him. For example, he enjoys a visual experience of seeing his arm rise. After successful brain surgery, things are now different. He now enjoys an experience of raising his arm. There is a phenomenal contrast, and arguably this connects to the role of the subject as merely passive in the perceptual case (merely seeing the arm rise) in contrast to the active (or actional) role in the case of raising his arm.

Can such phenomenal differences be captured in terms of manifest content as 'object-content'? Arguably not: The passive versus active role that our subject plays with respect to seeing his arm rise versus raising his arm, is not part of what is perceived or what is done (the objects of the visual experience and the intentional action respectively). Instead, it connects to the very doing or perceiving itself. The relevant differences arguably concern a representation of a mode-specific difference. In the passive case the subject represents that they are passive (or causally-inert) concerning what is seen. In the active case the subject represents that they cause the arm rising. Given this, we are led to posit mode-content. As Michael Schmitz, a defender of Intentionalism about Mode, puts it: 'In perceptual and actional experience, we experience our passive, respectively active, position toward the world...I represent this action from a position of directedness at causing it, of being committed and poised to cause it.... ${ }^{39}$ Generalising, mode-content would concern how

\footnotetext{
38 I thank a referee at Erkenntnis for suggesting this label. See also Schmitz (2018: 146).

39 See Schmitz (2018: 145-146). See also Recanati (2007: 127, 131-134) for a similar view, and a critique of Searle's (1983) approach of building these aspects into the 'object-content', based on a self-referential causal component, which Recanati claims involves the fallacy of misplaced information.
} 
the subject experiences and represents its relation to the states of affairs and other objects in the world, that is how the subject is related to the object it perceives, remembers, intends etc.

Intentionalism about Mode is a distinct view from Mode Intentionalism (it could be held without any commitment to non-content based differences explaining phenomenal contrasts). While an extensive critique of this view is not possible, let me document some reasons why we might prefer the Strong Intentionalist explanations offered here.

First, in the action case matters are complex, but arguably the contrast above is misleading. The relevant contrast should not be between a visual experience of one's arm raising and a raising of one's arm (i.e. perception vs perception plus intentional action) since the two experiences have a different overall manifest content (or object-content). They both have the same visual content, but the intentional action also has a manifest content related to the object of an intention. The more apt contrast might be compelled movement of my limb versus 'free' movement of my limb, evincing a phenomenal contrast between things that happen to me versus things that happen because of me (as passive in a compelled or causally inert sense, vs active in an actional sense).

But once so framed we are beyond the realm of sense-perception (and contrasts with it). Remember, the Strong Intentionalist's arguments were only concerned with phenomenal contrast cases involving sense-perception or its close cousins (visual imagination, imagistic memory etc.). So, while a view like Intentionalism about Mode may be required to explain phenomenal contrasts concerning the passivity of events concerning the subject's body with respect to which the agent is causally inert versus the 'active' character of intentional action, this doesn't undermine the Strong Intentionalist take on sense-perceptual experience.

As a second critical comment, Intentionalism about Mode incurs a specific theoretical cost. It implicates self-representational capacities: by way of mode-content the subject represents its own relation to states of affairs and objects in the world. For example, in the visual case, the view has it that the subject represents how it is related to the object it perceives, (e.g. that the (causal) relation is 'passive').

Yet the idea that in reasonably basic cases of sense-perceptual experience, say vision, the subject represents either itself or facts about itself is contentious. Several difficult questions arise. Do such self-representational capacities involve representing the relevant relations in terms of thought-contents, for example that $<$ my relation to the object is passive $>$ ? If so, this implicates conceptual capacities involving indexical, demonstrative and relational concepts, too demanding for basic cases.

Alternatively, if these mode-contents are intended to be non-cognitive-not involving theoretical thoughts about the relevant relations and differences-but are connected to how subjects experience, for example, the seeing itself, we still implicate the idea that subjects have the capacity for a distinctive form of (perhaps 
non-conceptual) self-representation. Namely, that whenever I have a visual experience, I also represent my experience itself (the seeing) under certain aspects, say as being 'passive'. One might think that even this kind of self-representational complexity, as implicated by positing mode-contents, is too demanding or at least in need of significant further defence. ${ }^{40}$

Finally, given how Intentionalism about Mode has been framed, it takes on the burden of explaining away the purported phenomenological transparency of senseperceptual experience. ${ }^{41}$ The idea that sense perceptual experience represents itself as being a certain way (say representing my relation to the object of perception as passive) potentially undermines its seeming to involve a direct, immediate non-inferential relation to the relevant object. If it involved such a manifest representation of itself in its overall content, then this may obstruct the phenomenology of what is experienced as a direct relation.

While these final comments are far from conclusive, they provide some reasons for preferring the Strong Intentionalist explanations of phenomenal contrasts offered in the bulk of this paper. Although the case against Intentionalism about Mode would have to be made in more detail than has been possible here.

\section{Conclusion}

This paper has demonstrated that the kind of phenomenal contrast cases appealed to in support of Mode Intentionalism allow for interpretations which do not require positing intentional modes as phenomenologically manifest aspects of sense-perceptual experience. As such, different arguments are required if Mode Intentionalism is to be a credible view of what determines the phenomenal character of sense-perceptual experience. Note though, what is also required to complete the critique is an extension of the arguments and considerations levelled in the sense-perceptual cases to non-perceptual modes. Finally, Intentionalism about Mode was considered, and reasons were provided for preferring the Strong Intentionalist explanations offered here.

Open Access This article is licensed under a Creative Commons Attribution 4.0 International License, which permits use, sharing, adaptation, distribution and reproduction in any medium or format, as long as you give appropriate credit to the original author(s) and the source, provide a link to the Creative Commons licence, and indicate if changes were made. The images or other third party material in this article are included in the article's Creative Commons licence, unless indicated otherwise in a credit line to the material. If material is not included in the article's Creative Commons licence and your intended use is not permitted by statutory regulation or exceeds the permitted use, you will need to obtain permission directly from the copyright holder. To view a copy of this licence, visit http://creativecommons.org/licen ses/by/4.0/.

\footnotetext{
${ }^{40}$ See Perry (1986), Campbell (1994: 4.1) and Evans (1982: 232-233) for criticism of implicating selfrepresentation in sense-perceptual experience. The alternative view finds expression in Hurley (1998: 207-247) and Bermúdez (1998: Ch.5).

${ }^{41}$ See Harman (1990) and Tye (2002).
} 


\section{References}

Bain, D. (2003). Intentionalism and pain. Philosophical Quarterly, 53(213), 502-523.

Bermúdez, J. (1998). The paradox of self-consciousness. Cambridge, MA: MIT Press.

Block, N. (1996). Mental paint and mental latex. Philosophical Issues, 7, 19-49.

Block, N. (2003). Mental paint. In M. Hahn \& B. Ramberg (Eds.), Essays on the philosophy of Tyler Burge, 165-200. Cambridge: MIT Press.

Brewer, B. (2011). Perception and its objects. Oxford: Oxford University Press.

Byrne, A. (2001). Intentionalism defended. Philosophical Review, 110(2), 199-240.

Campbell, J. (1994). Past, space, and self. Cambridge, MA: MIT Press.

Chalmers, D. J. (2004). The representational character of experience. In B. Leiter (Ed.), The future for philosophy (pp. 153-181). Oxford: Clarendon Press.

Chalmers, D. J. (2006). Perception and the fall from Eden. In T. S. Gendler \& J. Hawthrone (Eds.), Perceptual experience (pp. 49-125). Oxford: Oxford University Press.

Crane, T. (2000). Introspection, intentionality and the transparency of experience. Philosophical Topics, 28, 49-67.

Crane, T. (2001). Elements of mind: An introduction to the philosophy of mind. Oxford: Oxford University Press.

Crane, T. (2003). The intentional structure of consciousness. In A. Jokic \& Q. Smith (Eds.), Consciousness: New philosophical perspectives (pp. 1-27). Oxford: Oxford University Press.

Crane, T. (2009a). Intentionalism. In A. Beckermann \& B. P. McLaughlin (Eds.), The oxford handbook of the philosophy of mind (pp. 474-493). Oxford: Oxford University Press.

Crane, T. (2009b). Is perception a propositional attitude. Philosophical Quarterly, 59(236), 452-469.

Dennett, D. (1988). Quining qualia. In A. J. Marcel \& E. Bisiach (Eds.), Consciousness in contemporary science. Oxford: Oxford University Press.

Deonna, J., \& Teroni, F. (2012). An introduction to the philosophy of the emotions. London: Routledge.

Dretske, F. (2000). Perception, knowledge and belief. Cambridge: Cambridge University Press.

Evans, G. (1982). The varieties of reference. Oxford: Oxford University Press.

Harman, G. (1990). The intrinsic quality of experience. Philosophy of mind and action theory. Philosophical Perspectives, 4, 31-52.

Horgan, T., \& Tienson, J. (2002). The intentionality of phenomenology and the phenomenology of intentionality. In D. Chalmers (Ed.), Philosophy of mind: Classical and contemporary readings (pp. 520533). Oxford: Oxford University Press.

Hurley, S. (1998). Nonconceptual self-consciousness and agency: Perspective and access. Communication and cognition: An interdisciplinary quarterly journal, 30(3-4), 207-247.

Husserl, E. (2001[1901]) Logical investigations (J. N. Findlay, Trans.). London: Routledge.

Johnston, M. (2004). The obscure object of hallucination. Philosophical Studies, 120, 113-183.

Kind, A. (2003). What's so transparent about transparency? Philosophical Studies, 115, 225-244.

Kriegel, U. (2007). The phenomenologically manifest. Phenomenology and Cognitive Science, 6, 115-136.

Kriegel, U. (2015). Perception and imagination: A sartrean account. In S. Miguens, G. Preyer, \& C. Morando (Eds.), Pre-reflective consciousness: Sartre and contemporary philosophy of mind (pp. 245-276). London: Routledge.

Martin, M. (1993). Sense modalities and spatial properties. In N. Eilan, R. McCarthy, \& B. Brewer (Eds.), Spatial representation (pp. 206-218). Oxford: Basil Blackwell.

Martin, M. (1998a). Setting things before the mind. In Anthony O'Hear (Ed.), Current issues in philosophy of mind (pp. 157-179). Cambridge: Cambridge University Press.

Martin, M. (1998b). Bodily awareness: A sense of ownership. In J. Bermudez, A. Marcel, \& N. Eilan (Eds.), The body and the self (pp. 267-290). Cambridge, MA: MIT Press.

Mendelovici, A. (2013). Pure intentionalism about moods and emotions. In U. Kriegel (Ed.), Current controversies in philosophy of mind (pp. 135-157). London: Routledge.

Peacocke, C. (1983). Sense and content. Oxford: Oxford University Press.

Peacocke, C. (1992). A study of concepts. Cambridge: MIT Press.

Perry, J. (1986). Thought without representation. Supplementary Proceedings of the Aristotelian Society, 60, 137-152.

Recanati, F. (2007). Perspectival thought: A please for moderate relativism. Oxford: Oxford University Press. 
Rosenthal, D. (1986). Two concepts of consciousness. Philosophical Studies, 49, 329-359.

Schmitz, M. (2013). Limits of intention and the representational mind. In G. Seebass, M. Schmitz, \& P. M. Gollwitzer (Eds.), Acting intentionality: Individuals, Groups, Institutions (pp. 57-84). Berlin: DeGruyter.

Schmitz, M. (2017). What is a mode account of collective intentionality? In G. Preyer \& G. Peter (Eds.), Social ontology and collective intentionality: Critical essays on the philosophy of Raimo Tuomela with his responses (pp. 37-70). Cham: Springer.

Schmitz, M. (2018). Co-subjective consciousness constitutes collectives. Journal of Social Philosophy, 49(1), 137-160.

Searle, J. (1983). Intentionality: An essay in the philosophy of mind. New York: Cambridge University Press.

Searle, J. (1992). The rediscovery of the mind. Cambridge: MIT Press.

Shoemaker, S. (1996). The first-person perspective and other essays. Cambridge: Cambridge University Press.

Siegel, S. (2010). The contents of visual experience. Oxford: Oxford University Press.

Siewert, C. (2011). Phenomenal thought. In T. Bayne \& M. Montague (Eds.), Cognitive phenomenology (pp. 236-267). Oxford: Oxford University Press.

Soteriou, M. (2000). The Particularity of Visual Perception. European Journal of Philosophy, 8(2), $173-189$.

Speaks, J. (2009). Transparency, intentionalism, and the nature of perceptual content. Philosophy and Phenomenological Research, 79, 539-573.

Tye, M. (1995). Ten problems of consciousness. Cambridge: MIT Press.

Tye, M. (2000). Colour, consciousness, and content. Cambridge: MIT Press.

Tye, M. (2002). Representationalism and the transparency of experience. Nous, 36(1), 137-151.

Tye, M. (2014). Transparency, qualia realism and representationalism. Philosophical Studies, 170(39), 57.

Publisher's Note Springer Nature remains neutral with regard to jurisdictional claims in published maps and institutional affiliations. 